\title{
CHARACTERIZING PERFORMANCE VIA BEHAVIOR CO-OCCURRENCES IN A 3D COLLABORATIVE VIRTUAL LEARNING ENVIRONMENT: AN EXPLORATORY STUDY OF PERFORMANCE AND DESIGN
}

\author{
Krista Galyen \\ Dr. James Laffey, Dissertation Supervisor
}

\begin{abstract}
The iSocial 3D CVLE is an innovative design for addressing special needs at a distance that require social and active learning. This exploratory retrospective case study explored innovative methods of analyzing co-occurrences of behavior to gain insight into understanding and evaluating student performance and 3D CVLE design. Visualization techniques were employed to model student behavior within similarly structured activities. Linear mixed models revealed that student performance significantly differed across environments. In addition, environmental design attributes were identified through qualitative memos. General behavior patterns were associated with design environment attributes, warranting further study.
\end{abstract}

